\title{
Fingerprinting the origin of sheep milk products based on $\mathrm{H}-\mathrm{O}-\mathrm{C}-\mathrm{N}$ isotopes
}

\author{
Dotsika $E^{1,2 *}$, Bulleri $E^{2}$, Brunella $R^{2}$, Nudda $A^{3}$, Mele $M^{3}$, Battaglini $R^{2}$, Poutoukis $D^{4}$ and Chantzi $P^{1}$ \\ ${ }^{1}$ Laboratory of stable isotopes and radiocarbon, Institute of Nanoscience and Nanotechnology, NCSR Demokritos, 15310 Agia Paraskevi Attiki, Greece \\ ${ }^{2}$ Institute of Geosciences and Earth Resources, Via G. Moruzzi 1, 56124 Pisa, Italy \\ ${ }^{3}$ Dipartimento di Scienze Agraria, Alimentari e Agro-ambientali, via del Borghetto 80, 56124 Pisa, Italy \\ ${ }^{4}$ General Secretariat for Research and Technology, 10-14 Messogion, Athens, Greece
}

\begin{abstract}
The geographical origin of sheep milk was addressed through its isotopic composition in order to highlight the authenticity of the cheese "Pecorino Toscano DOP". Four farms from Manciano GR were selected where milk and watering water samples were collected for $\delta^{18} \mathrm{O}$ and $\delta \mathrm{D}$ isotope analysis. In addition, feed samples were collected and subjected to ${ }^{13} \mathrm{C}$ and ${ }^{15} \mathrm{~N}$ isotope analysis. In order to enhance the isotopic model, the same analyses were performed on samples from 4 farms located in northern Sardinia (Porto Torres) corresponding to a different geographical area with different environmental conditions. Results showed that the isotopic ratios of $\delta \mathrm{D}$ and $\delta^{18} \mathrm{O}$ in water samples reflected the hydrological regime of the study areas while $\delta^{15} \mathrm{~N}$ and $\delta^{13} \mathrm{C}$ reflected the feeding model. Climatic and geographical differences between Tuscany and Sardinia had a strong impact on the isotopic composition of the watering water samples distinguishing the isotopic composition of local dairy products.
\end{abstract}

\section{Introduction}

Dairy products constitute a typical example of the impact of food market globalization. Products that used to reflect specific geographical areas and traditional production methods, faced extinction as a result of the competition and the extended demands of modern food industry. On the other hand, the globalization of the food market also created a market for "luxury" or "exclusive" label, not designed for mass consumption, as the only opportunity of such localized production to survive. Therefore, the ability to authenticate the origin of a product has become increasingly important with respect to local and/or traditional production. This could be done if the particular regional features related to farms, mainly through watering water and feeding standards, as well as, production practices, could be traced in the final milk product (or byproducts). Among the various analytical techniques, with direct and indirect tracing indicators that have been used to identify the geographical origin of individual products and systems of food production, isotopic traceability, with dominant the stable isotope ratios of $\mathrm{H}-\mathrm{O}-\mathrm{C}-\mathrm{N}$, constitutes one of the most reliable methods [1-9]. Deuterium $\left(\mathrm{D} /{ }^{1} \mathrm{H}\right)$ and oxygen $\left({ }^{18} \mathrm{O} /{ }^{16} \mathrm{O}\right)$ isotopes mainly reflect the origin of the product as related to the geographical region and prevailing environmental conditions. Carbon $\left({ }^{13} \mathrm{C} /{ }^{12} \mathrm{C}\right)$ and nitrogen isotopes $\left({ }^{15} \mathrm{~N} /{ }^{13} \mathrm{~N}\right)$ related to the feeding regime adopted in the farms and to production practices as well.

Considering the existence of Italian excellence in the production of cheese in Tuscany this study aims to characterize the isotopic signature of "Pecorino Toscano DOP" protecting the authenticity of the label. The designation of "Pecorino Toscano DOP" concerns a cheese with the following characteristics: (a) soft or semi-hard cheese produced exclusively by sheep milk from farms that originate from the labeled area and (b) feeding standards in sheep farms covered by grazing or hay from natural pastures corresponding to the production area enhanced by feed concentrates.

\section{Isotopic background}

Water molecule isotopologues (comprising $\mathrm{D},{ }^{18} \mathrm{O}$ or both) are directly dependent on environmental conditions: precipitation, humidity, temperature [10]. The hydrogeological regime of each area characterizes the isotopic signature of available water (surface or ground water) that constitutes the "source" water (irrigation or/and drinking water). Therefore, analyses of these isotopes have been applied on milk water in order to trace the geographical origin of milk and milk products. In order to highlight the isotopic difference between the milk products that originate from different geographic areas, sheep milk from Sardinia was also studied as it stars on the DOP cheese production representing different environmental conditions. The carbon isotopes were used to identify the feed origin. The carbon isotope signal of a plant depends on its photosynthetic pathway. Typical $\delta^{13} \mathrm{C}$ values for $\mathrm{C} 4$ (Hatch-Slack, C4-dicarboxylic acid path-way) plants generally range from $-9 \%$ to $-19 \%$ o $[11,12]$ while for C3 (Calvin cycle) plants typically range from $-20 \%$ (open areas exposed to water stress) to -35\%o (closed canopy) $[11,12]$. There is a third photosynthetic pathway called CAM that presents $\delta^{13} \mathrm{C}$ values between the end-members of $\mathrm{C} 3$ and $\mathrm{C} 4$ types. Generally, C3 plants represent trees and bushes, temperate shrubs and herbs, as well as grasses that are favored to grow in cool environments, while C4 plants represent arid-adapted grasses, a few desert shrubs and herbs that presented in tropical, subtropical and temperate climates

Correspondence to: Dotsika Elissavet, Institute of Nanoscience and Nanotechnology, National Center for Scientific Research “Demokritos", 153 10 Aghia Paraskevi Attica; Institute of Geosciences and Earth Resources, Via G. Moruzzi 1, 56124 Pisa, Italy, Tel: 302106503305; Fax: 302106519430; E-mail e.dotsika@inn.demokritos.gr

Received: December 28, 2016; Accepted: January 17, 2017; Published: January 19,2017 
with warm summer rainfall. The CAM type actually reflects the plantsenvironment balance. So, the $\delta^{13} \mathrm{C}$ values of the particular feed model applied to each farm should correspond to the regional vegetation. Moreover, nitrogen isotopes $\left(\delta^{15} \mathrm{~N}\right)$ were used to reveal the agricultural practices e.g in feedlot or free grazing animals, grazing in mountainous or close to sea pasture lands, fertilization practices [13-16].

Consequently, the requirement for "Pecorino Toscano DOP” for sheep milk and feed supplies from the specific geographical area with specific agricultural practices could be reliably controlled based on $\delta^{2} \mathrm{H}-\delta^{18} \mathrm{O}, \delta^{13} \mathrm{C}$ and $\delta^{15} \mathrm{~N}$ isotopes respectively.

\section{Description of the study areas}

Tuscany and Sardinia areas selected under two basic rules that were discussed above: (1) both are dominant in DOP cheese production, therefore have well controlled sheep milk production and (2) they represent different environmental conditions. According to the Köppen classification (Kottek et al., 2006) [17] most of Sardinia, including Porto Torres, is characterized by a Csa climate, and only the central mountainous region where it is Csb. On the other hand Tuscany has Csa climate at the coastal region, Cfa at the southern inland parts (Manciano is at the border of those two) while the rest, and more extensive, inland areas are of Cfb type.

\section{Tuscany study area}

Tuscany exhibits different climate characteristics in different areas. Average annual temperatures, with highest values to be recorded around $16^{\circ} \mathrm{C}$ along the Tyrrhenian coast, tend to decrease moving inland and to the north; in the plains and inland valleys (middle Valdarno and Val di Chiana) maximum summer temperatures often approach $40^{\circ} \mathrm{C}$ while winter temperatures sometimes reach a few degrees below zero. Close to the Apennines along the east-west axis, between the Versilia and Casentino, the precipitation amounts often reach $2000 \mathrm{~mm}$ per year with the highest peaks at the Apuan Alps and the Tuscan-Emilian Apennines; on the contrary, along the coast of the Maremma and Argentario, $500 \mathrm{~mm}$ per year on average, are hardly reported. Reduced rainfall is also found at the areas of the Crete Senesi, the Val d'Orcia and Val di Chiana where the average annual values range between 600 $\mathrm{mm}$ and $700 \mathrm{~mm}$. Snowfall episodes are frequent in the Apennines and on the top of Mount Amiata covering the surrounding hilly areas, but rarely reach the plain and even less often the coast of north-central Tuscany. The sunshine duration (length of daylight) is a characteristic feature of the coast of Grosseto province, where it reaches values close to the reported absolute maximum values of the entire Italy, with annual average more than 7 hours per day (minimum in December with mean value 4 hours per day and maximum value more than 11 hours per day in June and July).

\section{Sardinia study area}

Sardinia is mainly characterized by a Mediterranean climate. Along the coastal areas the winters are mild, due to the presence of the sea, and the temperatures rarely fall below $0^{\circ} \mathrm{C}$. Summer period is hot and dry and is characterized by considerable evaporation. The low humidity and sea breezes make the high summer temperatures, which usually exceed $30^{\circ} \mathrm{C}$ or $35^{\circ} \mathrm{C}$, tolerable. Even in the interior plains and hilly areas the climate is typically Mediterranean however temperatures are lower at winter and higher at summer than the coastal areas due to the greater distance from the sea. In further inland areas such as the highlands and valleys, often nestle between the mountains, the climate becomes continental, with extreme temperature variations and minima that could reach even -10 to $-12^{\circ} \mathrm{C}$. In summer, very low temperatures could be reached, while in other areas they exceed $40^{\circ} \mathrm{C}$. At the mountains, the temperature falls below zero in winder as it often snows while summer is generally cool. During summer, the highest temperatures caused by the subtropical African anticyclone and accompanied by the warm air masses of the Sahara; in this case, the plains and inland valleys reach high maximum temperatures. In winter, the lowest temperatures are recorded upon the arrival of the cold air masses of Arctic origin transported by the Russian-Siberian anticyclone.

Rainfalls distribution is highly variable and irregular. Precipitation appears to be moderate along the coast, with mean annual values around $500-600 \mathrm{~mm}$, lower for the southern coast $(400 \mathrm{~mm})$. In particular, the location of Capo Carbonara records the minimum value in Italy which is $266 \mathrm{~mm}$ per year. In the inland areas the average rainfall is $500-800 \mathrm{~mm}$. Close to the mountains rainfall values reach or exceed $1000 \mathrm{~mm}$ per year with local peaks exceeding $1300-1400 \mathrm{~mm}$ in some areas. Given the dominance of westerly winds, the highest frequency of rainy days is to the western parts of the island, as it is directly exposed to winds accompanying disturbances coming from the Atlantic. The eastern areas present a lower frequency of rainy days due to orography, however, they are subject to heavy rains (hundreds of millimeters in 24 hours). Rainfall mainly occurs in the interval between October and April while between May and September the dry season extends with stable and sunny weather. About 50 river basins exist throughout Sardinia many of which host dams built. Snowfall is relatively frequent in altitude of 500-600 m above sea level and more intense at altitudes above $1000 \mathrm{~m}$. Sardinia is also a very windy region with northwest and southeast winds starring. The first during the winter are cold and violent while in summer they present moderate temperatures but the same intensity (which easily exceeds $100 \mathrm{~km} / \mathrm{h}$ ); the second (southeast winds) related to dust transport from the Sahara Desert and they are particularly harmful at the end of spring where they suffer intensify evapo-transpiration process causing water stress to non-irrigated crops.

\section{Material and methods}

\section{Sampling}

Two sampling projects were performed in Manciano at the province of Grosseto (January and April 2013) and one in Porto Torres (March 2013) at the province of Sassari. Sampling in Manciano concerned four sheep farms (M_1, M_2, M_3, M_4) that produce milk destined for the production of "Pecorino Toscano DOP" for the "Caseificio Sociale Manciano". Their distance from the sea is $18 \mathrm{~km}, 18 \mathrm{~km}, 16.5 \mathrm{~km}$ and $18.6 \mathrm{~km}$ respectively while their altitude is $65 \mathrm{~m}, 94 \mathrm{~m}, 105 \mathrm{~m}$ and $120 \mathrm{~m}$ respectively. In total eighty-eight sheep milk samples, feed supplies and watering water were collected. Regarding watering water samples, only one code was from a shallow water table which corresponds to the water network of Fiora, GR. The sampling period in January characterized by many precipitation episodes in contrast to the sampling period of April where these episodes were much fewer. In order to better reflect the characteristics of each farm in all periods, three water samples and milk samples were taken from each farm during each sampling period where their mean values presented in Table 1.

The sampling that carried out in Sardinia was performed with the collaboration of the Department of Agriculture of the University of Sassari and it concerns four farms (S_1, S_2, S_3 S_4) that produce milk destined for pecorino cheese in Porto Torres in Sassari province. Their distance from the sea is $1.4 \mathrm{~km}, 9.6 \mathrm{~km}, 2 \mathrm{~km}$ and $3.9 \mathrm{~km}$ respectively while their altitude is $74 \mathrm{~m}, 40 \mathrm{~m}, 36 \mathrm{~m}$ and $31 \mathrm{~m}$ respectively. In these 
Table 1.Isotopic data for milk and water samples from Tuscany and Sardinia farms. MA1, MA2 and SA denote watering water samples from Manciano 1 (January), Manciano 2 (April) and Porto Torres respectively, ML1, ML2 and SL refer to milk (whey) samples while ML1-D, ML2-D and SL-D to water samples extracted from milk. The numbers 1-4 correspond to the different farms.

\begin{tabular}{|c|c|c|c|c|c|c|c|}
\hline & Code & Data & Type & $\begin{array}{c}\delta^{18} \mathrm{O} \% \\
\text { V-SMOW }\end{array}$ & $\begin{array}{c}\delta^{2} \mathbf{H} \% \\
\text { V-SMOW }\end{array}$ & $\begin{array}{c}\text { an.unc. } \\
\delta^{18} \mathrm{O}(\% 0)\end{array}$ & \begin{tabular}{|l} 
an.unc. \\
$\delta^{2} \mathrm{H}(\% 0)$
\end{tabular} \\
\hline \multirow{8}{*}{ 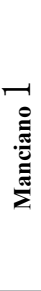 } & MA11 & $1 / 2013$ & Water & -6.3 & -41 & \pm 0.1 & \pm 1 \\
\hline & MA12 & $1 / 2013$ & Water & -8 & -47 & \pm 0.1 & \pm 1 \\
\hline & MA13 & $1 / 2013$ & Water & -8.3 & -53 & \pm 0.1 & \pm 1 \\
\hline & MA14 & $1 / 2013$ & Water & -8.3 & -52 & \pm 0.1 & \pm 1 \\
\hline & ML11 & $1 / 2013$ & Milk (whey) & - & - & - & - \\
\hline & ML12 & $1 / 2013$ & Milk (whey) & -0.8 & -20 & \pm 0.6 & \pm 6 \\
\hline & ML13 & $1 / 2013$ & Milk (whey) & - & - & - & - \\
\hline & ML14 & $1 / 2013$ & Milk (whey) & -1.9 & -25 & \pm 0.6 & \pm 6 \\
\hline \multirow{9}{*}{ 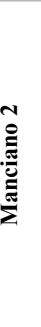 } & MA21 & $4 / 2013$ & Water & -6.5 & -41 & \pm 0.1 & \pm 1 \\
\hline & MA22 & $4 / 2013$ & Water & -8.1 & -51 & \pm 0.1 & \pm 1 \\
\hline & MA23 & $4 / 2013$ & Water & -8 & -48 & \pm 0.1 & \pm 1 \\
\hline & ML21 & $4 / 2013$ & Milk (whey) & 0.5 & -14 & \pm 0.6 & \pm 6 \\
\hline & ML22 & $4 / 2013$ & Milk (whey) & 1 & -20 & \pm 0.6 & \pm 6 \\
\hline & ML23 & $4 / 2013$ & Milk (whey) & 0.3 & -12 & \pm 0.6 & \pm 6 \\
\hline & ML21-D & $4 / 2013$ & Milk distillate & 1.2 & -8 & \pm 0.1 & \pm 1 \\
\hline & ML22-D & $4 / 2013$ & Milk distillate & 1.3 & -10 & \pm 0.1 & \pm 1 \\
\hline & ML23-D & $4 / 2013$ & Milk distillate & 1.8 & -12 & \pm 0.1 & \pm 1 \\
\hline \multirow{8}{*}{ 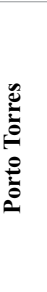 } & SA1 & $3 / 2013$ & Water & -6.6 & -37 & \pm 0.1 & \pm 1 \\
\hline & SA2 & $3 / 2013$ & Water & -5.9 & -36 & \pm 0.1 & \pm 1 \\
\hline & SA3 & $3 / 2013$ & Water & -6.9 & -38 & \pm 0.1 & \pm 1 \\
\hline & SA4 & $3 / 2013$ & Water & -5.8 & -34 & \pm 0.1 & \pm 1 \\
\hline & SL1 & $3 / 2013$ & Milk (whey) & - & - & - & - \\
\hline & SL2 & $3 / 2013$ & Milk (whey) & 2 & -25 & \pm 0.6 & \pm 6 \\
\hline & SL3 & $3 / 2013$ & Milk (whey) & - & - & - & - \\
\hline & SL4 & $3 / 2013$ & Milk whey) & 1 & -20 & \pm 0.6 & \pm 6 \\
\hline
\end{tabular}

farms, also, sheep milk, feed supplies and watering water samples were collected, while the letter corresponds to medium depth boreholes $(40 \mathrm{~m}-80 \mathrm{~m})$ and one sample was found to derive from shallow groundwater (7 m for S_4).

The sampling was performed according to the protocols for the determination of oxygen and deuterium isotope in milk water and carbon and nitrogen isotopes in feed supplies. For milk water samples, $50 \mathrm{ml}$ sterile bottles with a safety lid were used while for feed samples plastic bags were used labeled properly. Both of them were frozen immediately until the analysis and only watering water samples $(50 \mathrm{ml}$ sterile bottles with safety lid) were stored in a refrigerator at about $4^{\circ} \mathrm{C}$.

\section{Stable isotope analysis}

All measurements were carried out in Laboratory of Stable Isotope and radiocarbon, Institute of Nanoscience and Nanotechnology, NCSR Demokritos (Athens, Greece) under laboratory standards that were periodically calibrated according to the international standards recommended by the International Atomic Energy Agency (IAEA).

Stable isotope analysis of oxygen-18 and deuterium: The isotopic composition of hydrogen (D) and oxygen $\left({ }^{18} \mathrm{O}\right)$ were measured on a continuous flow Finnigan DELTA V plus stable isotope mass spectrometer according to the procedures described by Hilkert, Avak [18] and Duhr, Hilkert [19]

Samples were introduced into $10 \mathrm{ml}$ containers previously filled with a mixture gas of $0.3 \% \mathrm{CO}_{2} / \mathrm{He}$ at atmospheric pressure. The containers were placed in an agitator and equilibrated to $25^{\circ} \mathrm{C}$ degrees for at least $24 \mathrm{~h}$, the time required for equilibrium to be reached.
The isotope ratio $\mathrm{D} /{ }^{1} \mathrm{H}$ was determined by $\mathrm{H}_{2}$ generated by equilibration with $2 \% \mathrm{He} / \mathrm{H}_{2}$.

The results are expressed in standard delta notation $(\delta)$ as per mil (\%) deviation from the standard V-SMOW as:

$$
\delta=\left(\left(\mathrm{R}_{\text {sample }}-\mathrm{R}_{\text {standard }}\right) / \mathrm{R}_{\text {standard }}\right) \times 1000
$$

where

$\mathrm{R}_{\text {sample }}$ and $\mathrm{R}_{\text {standard }}=\mathrm{D} /{ }^{1} \mathrm{H}$ or ${ }^{18} \mathrm{O} /{ }^{16} \mathrm{O}$ ratios of sample and standard respectively.

Attention was paid in improving the analytical method for the determination of deuterium by reducing the sensitivity. Therefore a cryogenic vacuum line was set up in the Institute of Geosciences and Earth Resources, CNR, Pisa through which, we were allowed to reach a sensitivity of $0.1 \%$ for ${ }^{18} \mathrm{O}$ and $1 \%$ for $\mathrm{D}$. Measurement precisions for water samples, based on the repeated analysis were $0.1 \%$ and $1 \%$ o for $\delta^{18} \mathrm{O}$ and $\delta \mathrm{D}$ respectively while for milk water samples (whey) the precisions were $0.6 \%$ and $6 \%$ for $\delta^{18} \mathrm{O}$ and $\delta \mathrm{D}$ respectively.

Stable isotope analysis of carbon-13 and nitrogen-15: The isotope values of $\delta^{13} \mathrm{C}$ and $\delta^{15} \mathrm{~N}$ were determined using a Flash Elemental Analyzer with column combustion at $1020^{\circ} \mathrm{C}$ coupled with a Thermo Scientific Delta V Plus stable isotope mass spectrometer. The isotopic ratio for $\delta^{13} \mathrm{C}$ is expressed versus $\mathrm{PDB}$ standards and for ${ }^{15} \mathrm{~N}$ versus atmospheric nitrogen. The results are expressed in standard delta notation $(\delta)$ as per mil (\%o) deviation from the standard V-PDB and $\mathrm{V}$-AIR for ${ }^{13} \mathrm{C}$ and ${ }^{15} \mathrm{~N}$ respectively according to equation (1)

where

$\mathrm{R}_{\text {sample }}$ and $\mathrm{R}_{\text {standard }}={ }^{13} \mathrm{C} /{ }^{12} \mathrm{C}$ or ${ }^{15} \mathrm{~N} /{ }^{14} \mathrm{~N}$ ratios of the sample and standard respectively.

The analytical precision of measurement was $0.1 \%$ and $0.2 \%$ for $\delta^{13} \mathrm{C}$ and $\delta^{15} \mathrm{~N}$ respectively.

\section{Results}

\section{Oxygen-18 and deuterium isotopes in water and milk samples}

The results of the analyses conducted on milk water are shown in Table 1. It is evident that the uncertainty referring to measured $\delta^{18} \mathrm{O}$ and $\delta \mathrm{D}$ values in water extracted from milk with the cryogenic vacuum line $\left(0.1 \%\right.$ for $\delta^{18} \mathrm{O}$ and $1 \%$ for $\left.\delta \mathrm{D}\right)$ is much lower compared to the analysis conducted on the whey obtained after the acidification of natural milk ( $0.6 \%$ or for $\delta^{18} \mathrm{O}$ and $6 \%$ for $\left.\delta \mathrm{D}\right)$.

It is clearly evident (Table 1) that the isotope values of water extracted from milk are significantly more enriched than watering water samples, independently of their origin (Manciano or Porto Torres) or the sampling period (January, April or March). With respect to $\delta^{18} \mathrm{O}$ values, watering water samples range from $-8.3 \%$ to $-6.3 \%$ for Manciano_1, from $-8.1 \%$ o to $-6.5 \%$ for Manciano_2 and from $-6.9 \%$ o to $-5.8 \%$ for Porto Torres; milk samples range from $-1.9 \%$ o to $-0.8 \%$ for Manciano_1, from $0.3 \%$ to $1.0 \%$ o for Manciano_2 and from $1.0 \%$ to $2.0 \%$ for Porto Torres (Table 1). Regarding deuterium isotope values the range presented higher. Watering water samples range from $-53 \%$ to $-41 \%$ or for Manciano_ 1 , from $-51 \%$ o to $-41 \%$ for Manciano_2 and from $-38 \%$ to $-34 \%$ for Porto Torres; milk samples range from $-25 \%$ to $-20 \%$ o for Manciano_1 and Porto Torres and from -20\%o to $-12 \%$ for Manciano_2 (Table 1). Generally mean isotope values (oxygen and deuterium) of watering water samples from Manciano_1 and Manciano_2 are quite close in contrast to Porto Torres where more 
enriched values were found.

Moreover, regarding oxygen-18 isotope values of milk samples appreciable differences were observed relating to different origins; Porto Torres presented the most positive mean value $(1.5 \%)$ followed by Manciano_2 $(0.6 \%$ ) and Manciano_1 with negative mean value $(-1.4 \%$ o). Deuterium isotope mean value of milk seems to differentiate with respect to sampling period.

In Table 2 the row named as "shift" corresponds to the variation of the mean isotopic values between the intake water and milk product reflecting the isotopic fractionation that occurs through the path of all the metabolic processes. A first approach results to a distinction between the "shift" reported for Manciano_1 (6.4\%o and 26\%o for $\delta^{18} \mathrm{O}$ and $\delta \mathrm{D}$ respectively), Manciano_2 (8.1\%o and $31 \%$ for $\delta^{18} \mathrm{O}$ and $\delta \mathrm{D}$ respectively) and that of Porto Torres $\left(7.8 \%\right.$ and $14 \%$ for $\delta^{18} \mathrm{O}$ and $\delta \mathrm{D}$ respectively) according to different origins and different sampling periods.

\section{Carbon-13 and nitrogen-15 isotopes of feed supplies}

Each farmer applies different diet model resulting to a unique isotopic signature related to the feed composition. The aim was to determine the isotopic signature of carbon-13 and nitrogen-15 in all components of each diet type in order to identify any differences occur in sheep milk due to the geographical origin of grass grown in Manciano and Porto Torres. The feed composition varies (greater in April) depending on the availability of each grass type in different seasons. The following describes in detail the feed composition for each farm in Manciano:

- Farm M_1 Manciano_1: 40\% oat hay/clover, 30\% medick cultivation of $2^{\text {nd }}$ cut and $30 \%$ supply from Agricultural Consortium of Tuscany (ACT)

- Farm M_2 Manciano_1: 40\% oat hay, 30\% swaddled medick cultivation of $1^{\text {st }}$ cut and $30 \%$ supply from ACT

- Farm M_3 Manciano_1: 70\% oat hay and 30\% supply from ACT

- Farm M_4 Manciano_1: 65\% oat hay and 35\% supply from ACT

The feed composition in all farms (M_1, M_2, M_3, M_4) of Manciano_2 is the same and consists of 57\% pasture, $24 \%$ supply from ACT and $19 \%$ oat hay/clover. At the following Table $3, \delta^{13} \mathrm{C}$ and $\delta^{15} \mathrm{~N}$ values of feed types are presented.

Tuscan samples range from $-29 \% 0 \delta^{13} \mathrm{C}$ (related to ACT feed) to $-25.1 \%$ o $\delta^{13} \mathrm{C}$ (related to the oat hay samples from farm 3 in Manciano_1 and the pasture from Manciano_2). The ACT feed supply consists of a mixture with raw feed material the composition of which is: Sorghum $24 \%$, Orzo 20\%, Soybean 13\%, Extruded linseed 10\%, Middlings $8.2 \%$, Sunflower seed $6 \%$, Cane molasses 5\%, Medic cultivation $4 \%$, Soybean oil 3\%, Beet pulp 2\%, Calcium carbonate 1.5\%, Dicalcium phosphate $0.9 \%$, Sodium bicarbonate $0.8 \%$, Sodium chloride $0.6 \%$, ACT sheep

Table 2. Mean values andstandard deviationfor $\delta^{18} \mathrm{O} \% \mathrm{~V}$-SMOW and $\delta \mathrm{D} \% \mathrm{~V}-\mathrm{SMOW}$ values of water and milk samples in Manciano and Porto Torres farms for the different sampling periods.

\begin{tabular}{|c|c|c|c|c|c|c|c|c|c|c|c|c|c|c|c|c|c|c|}
\hline \multicolumn{7}{|c|}{ Manciano 1} & \multicolumn{6}{|c|}{ Manciano 2} & \multicolumn{6}{|c|}{ Porto Torres } \\
\hline & Mean & St.Dev & $\mathbf{N}$ & Mean & St.Dev & $\mathbf{N}$ & Mean & St.Dev & $\mathbf{N}$ & Mean & St.Dev & $\mathbf{N}$ & Mean & St.Dev & $\mathbf{N}$ & Mean & St.Dev & $\mathbf{N}$ \\
\hline & \multicolumn{3}{|c|}{${ }_{8}^{18} 0$} & \multicolumn{3}{|c|}{$\delta^{2} \mathbf{H}$} & \multirow{2}{*}{\multicolumn{3}{|c|}{$\begin{array}{l}18 \\
8{ }^{18}\end{array}$}} & \multicolumn{4}{|c|}{$\delta^{2} \mathbf{H}$} & \multicolumn{2}{|l|}{${ }_{8}^{18} 0$} & \multicolumn{3}{|c|}{$\delta^{2} \mathbf{H}$} \\
\hline $\mathrm{H}_{2} \mathrm{O}$ & -7.7 & 1 & 4 & -48 & 6 & 4 & & & & -47 & 5 & 3 & -6.3 & 0.5 & 4 & -36 & 2 & 4 \\
\hline Milk & -1.4 & 0.8 & 2 & -23 & 4 & 2 & 0.6 & 0.4 & 3 & -15 & 4 & 3 & 1.5 & 0.7 & 2 & -23 & 4 & 2 \\
\hline shift & 6.4 & & & 26 & & & 8.1 & & & 31 & & & 7.8 & & & 14 & & \\
\hline
\end{tabular}

Table 3. $\delta^{13} \mathrm{C}$ and $\delta^{15} \mathrm{~N}$ isotopic data from feed supplies in Manciano and Porto Torres farms ("ACT: Agricultural Consortium of Tuscany).

\begin{tabular}{|c|c|c|c|c|c|c|c|c|}
\hline & $\mathbf{N}^{\circ}$ Farm & Data & Sample code & Feed type & $\begin{array}{l}\delta^{13} \mathrm{C} \% \\
\text { V-PDB }\end{array}$ & $\begin{array}{l}\delta^{15} \mathbf{N} \% \\
\text { V-AIR }\end{array}$ & $\begin{array}{c}\text { an.unc. } \\
\delta^{13} \mathrm{C}(\% \%)\end{array}$ & $\begin{array}{c}\text { an.unc. } \\
\delta^{15} \mathrm{~N}(\%)\end{array}$ \\
\hline \multirow{7}{*}{ 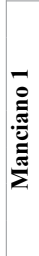 } & 1 & $1 / 2013$ & $\mathrm{Fi}$ av_trif & oat hay/clover medick & -25.3 & 2 & \pm 0.1 & \pm 0.2 \\
\hline & 1 & $1 / 2013$ & Fi_m & cultivation of 2 nd cut medick & -26.1 & 2.4 & \pm 0.1 & \pm 0.2 \\
\hline & 2 & $1 / 2013$ & Fa_m & cultivation of 1 st cut & -26.5 & 2.6 & \pm 0.1 & \pm 0.2 \\
\hline & 2 & $1 / 2013$ & Fi_av & oat hay & -25.3 & 3.1 & \pm 0.1 & \pm 0.2 \\
\hline & 3 & $1 / 2013$ & $\mathrm{Fi}$ av & oat hay & -25.1 & 3.8 & \pm 0.1 & \pm 0.2 \\
\hline & 4 & $1 / 2013$ & $\mathrm{Fi}$ av & oat hay & -25.2 & 2.8 & \pm 0.1 & \pm 0.2 \\
\hline & $*$ & $1 / 2013$ & Form & ACT & -28.2 & 2.6 & \pm 0.1 & \pm 0.2 \\
\hline \multirow{4}{*}{ 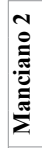 } & 1 & $4 / 2013$ & Pasc & pasture & -25.2 & 3.1 & \pm 0.1 & \pm 0.2 \\
\hline & 2 & $4 / 2013$ & Pasc & pasture & -25.3 & 2.5 & \pm 0.1 & \pm 0.2 \\
\hline & 3 & $4 / 2013$ & Pasc & pasture & -25.1 & 2.1 & \pm 0.1 & \pm 0.2 \\
\hline & $*$ & $4 / 2013$ & Form & ACT & -29 & 4.2 & \pm 0.1 & \pm 0.2 \\
\hline \multirow{11}{*}{ 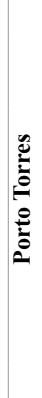 } & 1 & $3 / 2013$ & Pasc & pasture & -27.2 & 4.1 & \pm 0.1 & \pm 0.2 \\
\hline & 1 & $3 / 2013$ & $\mathrm{c}+\mathrm{Fi}$ & mix condensate feed $\&$ hay & -26.8 & 5.2 & \pm 0.1 & \pm 0.2 \\
\hline & 2 & $3 / 2013$ & Pasc & pasture & -26.9 & 4.8 & \pm 0.1 & \pm 0.2 \\
\hline & 2 & $3 / 2013$ & $\mathrm{Fi}$ & hay & -27.3 & 6.1 & \pm 0.1 & \pm 0.2 \\
\hline & 2 & $3 / 2013$ & $\mathrm{c}$ & composed food of maize, sugar beet pulp and pellets trade & -23.6 & 3.2 & \pm 0.1 & \pm 0.2 \\
\hline & 3 & $3 / 2013$ & Pasc & pasture & -27.1 & 5.2 & \pm 0.1 & \pm 0.2 \\
\hline & 3 & $3 / 2013$ & $\mathrm{Fi}$ & hay & -27.5 & 4.8 & \pm 0.1 & \pm 0.2 \\
\hline & 3 & $3 / 2013$ & $\mathrm{c}$ & composed food of sugar beet pulp and pellets trade & -27.1 & 6.2 & \pm 0.1 & \pm 0.2 \\
\hline & 4 & $3 / 2013$ & Pasc & pasture & -27.2 & 5.9 & \pm 0.1 & \pm 0.2 \\
\hline & 4 & $3 / 2013$ & Fi & hay & -28.1 & 6.2 & \pm 0.1 & \pm 0.2 \\
\hline & 4 & $3 / 2013$ & $\mathrm{c}$ & composed food of sugar beet pulp and pellets trade & -27.4 & 5.6 & \pm 0.1 & \pm 0.2 \\
\hline
\end{tabular}


milk $0.5 \%$, Binder $0.25 \%$, Selenium $0.2 \%$ and metio-prc $0.05 \%$. The heterogeneity of the mixture with respect to carbon-13 isotopic content is evident, since on the one hand there is a significant proportion of sorghum which belongs to $\mathrm{C} 4$ plants and leads to a depletion of $\delta^{13} \mathrm{C}$ values, while on the other hand various quantities of strongly $\delta^{13} \mathrm{C}$ negative components such as extruded linseed and soybean oil, are also included.

Carbon isotope values $\delta^{13} \mathrm{C}$ for the Sardinian feed ranged from $-28.1 \%$ to $-26.8 \%$ except for the condensate sample of farm S_2 (Table 3 ). The fact that this sample is made by maize flour (C4 plant), could justify a more positive $\delta^{13} \mathrm{C}$ value compared to the other Sardinian and Tuscan samples. Regarding ${ }^{15} \mathrm{~N} /{ }^{14} \mathrm{~N}$ isotopes all the samples are enriched in $\delta^{15} \mathrm{~N} \%$ compared to the nitrogen-15 isotopic composition of atmosphere ( $0 \%$ by definition). Specifically, $\delta^{15} \mathrm{~N} \%$ o values for Tuscan feed samples vary between $2 \%$ referring to the oat hay/clover sample from farm M_1 in Manciano_1 and 4.2\%o for the ACT feed sample from Manciano_2. For the Sardinian feed samples $\delta^{15} \mathrm{~N} \%$ values vary between $3.2 \%$ for the composed food of farm S_2 and $6.2 \%$ for composed food and hay samples from farm S_4.

\section{Discussion}

\section{Oxygen-18 and deuterium isotopes in water and milk samples}

The $\delta^{18} \mathrm{O}$ and $\delta \mathrm{D}$ values of intake water in Manciano and Porto Torres farms are shown in Figure 1. At the same figure are also pictured the Global Meteoric Water Line according to the equation [20]:

$$
\delta \mathrm{D}=8 \times \delta^{18} \mathrm{O}+10
$$

and the Local Meteoric Water Line (LMWL) according to the equation [21]:

$$
\delta \mathrm{D}=5.7 \delta^{18} \mathrm{O}-2.4
$$

Sardinian water samples appear to be more enriched than those of Tuscan where water samples from farm M_1 in Manciano (MA11 and MA21) exhibited more positive values compared to the rest. The maximum variation was reported for the water sample from the farm S_4 in Porto Torres and corresponds to shallow groundwater with depth about $7 \mathrm{~m}$. In contrast, the comparison with the samples taken from the Manciano M_2, M_3 and M_4 farms, which related to the

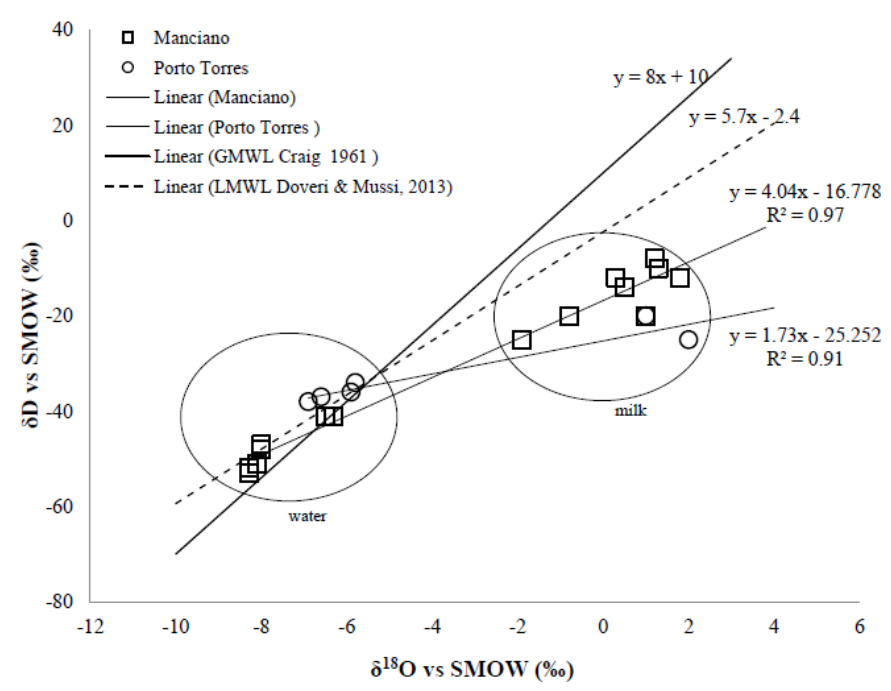

Figure 1. $\delta$ D \% VSMOW and $\delta^{18} \mathrm{O} \%$ VSMOW isotope values for watering water and milk water samples from Tuscany and Sardinia
Fiora hydraulic network, highlights the significant isotopic differences between the waters of Sardinia and Tuscany as the last originate from a catchment located in Mount Amiata with mean altitude more than $1400 \mathrm{~m}$. Thus the two study areas are characterized by an isotopic composition of watering water sufficiently different that makes them easily distinguishable. The isotopic composition of waters referring to Canino, Sassari [22] and Capo Caccia (IAEA) are also taken into account in order to draw a better portrait of the isotopic composition of meteoric waters from the study areas.

All milk samples exhibit enrichment with respect to water samples presenting a slope that reminds waters that have undergone evaporation process (Figure 1). Furthermore, it is pointed out that milk water samples extracted by cryogenic vacuum line (ML21-D, ML22-D and ML23-D), generally present an isotopic composition more enriched compared to those corresponding to natural formation of whey (ML21, ML22 and ML23) reflecting the effectiveness of the extraction technique (cold procedure). In fact, in this process, by the end of the extraction the isotope values become depleted because of the ease of light isotope to pass during the gas face. An additional control for the proper function of cryogenic vacuum line was performed considering the mass balance between the original matrix (milk) and the final (by)products (extracted water and residual dry weight); the results were acceptable with $\pm 0.5 \%$ deviation.

Despite the limited availability of Sardinian data (isotopic data for two milk samples) it was observed that they present a less pronounced enrichment in deuterium than those of Manciano. This is evident from the watering-milk water mixing lines given in Figure 1 Porto Torres mixing line presents a slope significantly different and lower (about 1.7) compared to the Manciano mixing line with a slope of about 4.04. The different slope coefficients could be attributed to a different hydrological regime at the areas where the sheep farms located (Sardinia and Tuscany). In fact, oxygen-18 and deuterium values in animal body water, and then in the produced milk, consist of a mixture derived from atoms of oxygen- 18 and deuterium from watering water, feed, water contained in food and atmospheric oxygen [23]. Some hydrogen and oxygen atoms are passively diffused in the body water pool, through intake water for example [24], while others are added from scratch due to the water production during food or atmospheric oxygen metabolism. The isotopic composition of produced metabolic water is generally enriched with respect to watering water. Although the intake water constitutes the major source, the $\delta^{18} \mathrm{O}$ and $\delta \mathrm{D}$ values could be significantly altered by the metabolic water $[13,25,26]$. The extent of enrichment between milk water and watering water, should be correlated with the total volume of intake water by animal: the greater the intake water volume, the higher the similarity between the two aqueous matrixes as the contribution of watering water is increased compared to metabolic water in the animal body water pool. Based on the above it is assumed that Sardinian sheep farms might exhibit a higher volume of intake water as the isotopic signature of their milk water is closer to the isotopic signature of the local watering water in contrast to the isotopic values for the Manciano sheep farms. Other studies have documented an enrichment about $2-6 \%$ in ${ }^{18} \mathrm{O} /{ }^{16} \mathrm{O}$ between cow's intake water and cow's milk water.

Another observation concerns the small difference between milk water from farm M_1 in Manciano_1 (ML2 and ML3) compared to watering water. In a common evaporative process this observed slight difference would be consistent with temperature variations related to seasonal variations. However, in complicated systems, as those that take place within the body for the metabolism of foods and milk synthesis, 
such a parallelism could be risky, even if it seems possible that to some extent the two phenomena could be assimilated.

However, regardless the reasons that control the $\delta^{18} \mathrm{O}$ and $\delta \mathrm{D}$ enrichment of milk, it seems possible to discriminate the origin of milk samples (Sardinia and Tuscan) based on isotopic analysis of intake water.

\section{Carbon-13 and nitrogen-15 isotopes of feed supplies}

Since the isotopic signal of the feed supplies depends on their photosynthetic pathway, which in its turn correlates with the environmental conditions, the geographic characteristics and the feed composition that is used in each farm, it is believed, as it has already been analyzed above, that $\delta^{13} \mathrm{C}$ and $\delta^{15} \mathrm{~N}$ isotopic values of feed could be used as an additional tool for milk authentication. Feed samples presented a typical composition of C3 plants dependent on $\delta^{13} \mathrm{C}$ values [-22\% to $-30 \%$ o [13,27-35]. In more detail, Porto Torres samples exhibit more depleted $\delta^{13} \mathrm{C}$ values than those of Manciano except for the samples that correspond to the ACT feed in Mancianol and 2 and the concentrated feed supplies of farm S_2 in Porto Torres. The last refers to composed food with components of maize, sugar beet pulp and pellets trade, thus, the enrichment in $\delta^{13} \mathrm{C}$ could be due to the presence of maize, a $\mathrm{C} 4$ plant, which enables more positive isotopic composition. Since all the Sardinian concentrate feed samples have the same nominal composition, it is supposed that in farm S_2 of Porto Torres the feed standards present a higher member of maize than the other mixtures. Contrary, concerning ACT Form samples (F), the relative isotopic depletion that is presented compared to the rest feed types is attributable to the presence of soybean oil (13\%) and extruded linseed (10\%) which have an isotopic signal of about $-32 \%$ (Dotsika, 2013 unpublished data). Despite the fact that ACT feed type, consist of $24 \%$ sorghum (C4 plant) it is evident that the contribution of the isotopically depleted components is particularly significant.

Nitrogen-15 isotopic values of dairy products reflect the plants that were consumed by animals and related to the original isotopic composition of the soil [13-16]. $\delta^{15} \mathrm{~N}$ values range between $2.0 \%$ and $6.2 \%$. These values are in agreement with the data published in the literature $[26,30]$. However, Tuscan feed samples present lower values of $\delta^{15} \mathrm{~N}$ compared to Sardinian ones; this difference occurs whatever the feed type is (pasture, fodder, hay or condensed feed type). An exception constitutes of pasture from farm S_1 and condensed feed type samples from farm S_2 in Porto Torres, with less enriched values than those that generally characterize the Sardinian samples. Nitrogen-15 isotopic values of plants are mainly determined by the isotopic composition and the availability of nitrogen in the soil nitrate and ammonium forms [36,37]. In turn, the isotopic composition of $\delta^{15} \mathrm{~N}$ in soil depends on the climatic and geographical conditions [38] as well as on agricultural practices such as fertilization. Generally, the application of organic fertilizers or the practice of intensive agriculture, leads to an increase in soil $\delta^{15} \mathrm{~N}$ values [39] and therefore to an increase in $\delta^{15} \mathrm{~N}$ values of plants that grow on the same soil. The intensive use of organic fertilizers and other practices such as the dryness of the soil, salinity and the proximity to the sea tend to increase the ratio ${ }^{15} \mathrm{~N} /{ }^{14} \mathrm{~N}$ in soil, plant and animal products. Plants that use as major source the atmospheric nitrogen (about $0 \%$ ) lead to animal products with lower $\delta^{15} \mathrm{~N}$ values compared to those that use soil as their major nitrogen source [40].

In samples Fi_av_trif, $F i \_m$ and $F a \_m$ from Manciano the contribution of clover and medick, seems to partly justify the lower $\delta^{15} \mathrm{~N}$ values compared to the samples that corresponds to oat hay only (Fi_av).
Finally, based on the above, it can be assumed that two factors that distinguish the two sheep milk origins related to the different climatic and geographic setting that characterize each study area (Tuscan and Sardinia). It has been documented by Heaton [38] that there is a negative relationship between precipitation and $\delta^{15} \mathrm{~N}$, therefore more positive values of $\delta^{15} \mathrm{~N}$ in arid climates than those in more humid environments should be expected. Indeed, this trend is consistent with the observed $\delta^{15} \mathrm{~N}$ values and the environmental regime of the study areas. Tuscany with less positive $\delta^{15} \mathrm{~N}$ values presents higher mean annual precipitation $(1000 \mathrm{~mm} /$ year $)$ than Sardinia that presents mean annual precipitation about $350 \mathrm{~mm} /$ year and more positive $\delta^{15} \mathrm{~N}$ values. Furthermore, the data agree with a slope of $-0.39 \%$ o $\delta^{15} \mathrm{~N} / 100$ of annual rain that proposed by Heaton [38] further confirming the observed interaction.

This relation used to assess the extent of the influence of the precipitation factor by determining the expected differentiation between the two study areas. Considering the mean $\delta^{15} \mathrm{~N}$ for the two study areas: 2.7\% Manciano and 5.4\% to Porto Torres excluding Sardinian sample c from farm S_2 and ACT Form samples from Manciano which, to some extent exhibit anomalous values, it appears that the observed difference in $\delta^{15} \mathrm{~N}$ can be explained by the precipitation regime: $2.5 \%$ theoretical against $2.7 \%$ observed.

As precipitation has been identified as the major factor that controls $\delta^{15} \mathrm{~N}$ values an attempt was made to be highlight additional local factors. The distance from the sea exhibited an interesting correlation with feed samples associated with pasture. In both study areas, there is a positive correlation between $\delta^{15} \mathrm{~N}$ and the distance from the sea, with a significant $\mathrm{r}^{2}$ coefficient, more so in the case of Porto Torres (Figure 2). However, this observation conflicts the remarks by Heaton [38] supporting the reduction of $\delta^{15} \mathrm{~N}$ values with increasing distance from the sea.

Figure 3 summarizes the observed $\delta^{13} \mathrm{C}$ and $\delta^{15} \mathrm{~N}$ isotopic differences in the feed components of the two study areas which are clearly distinct and therefore satisfy the required condition to be used as tools for verifying the authenticity of the dairy products.

\section{Conclusions}

This paper deals with the authentication of the origin of "Pecorino

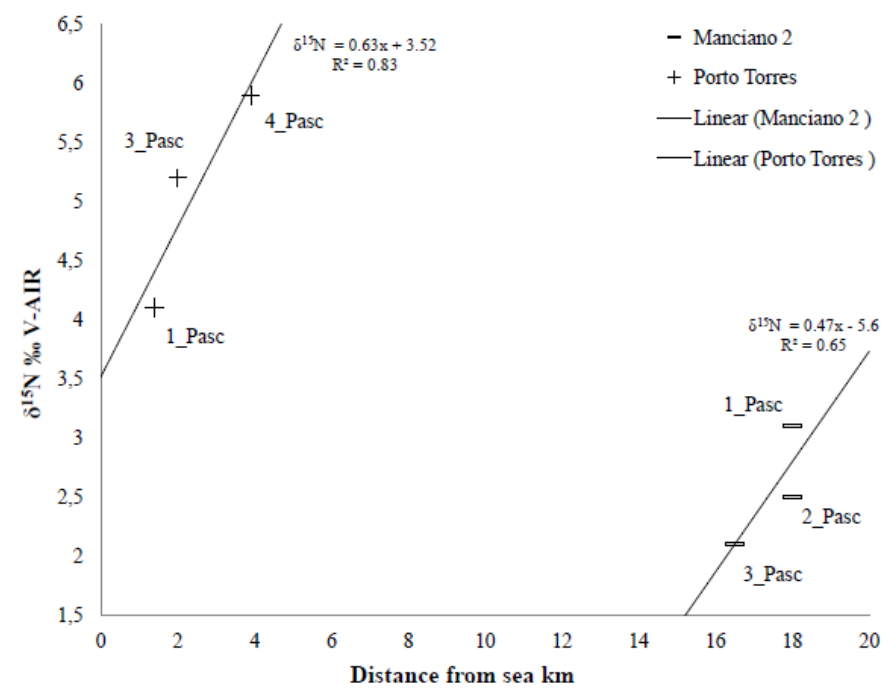

Figure 2. Relation between feed and distance from the sea for the studied farms. 


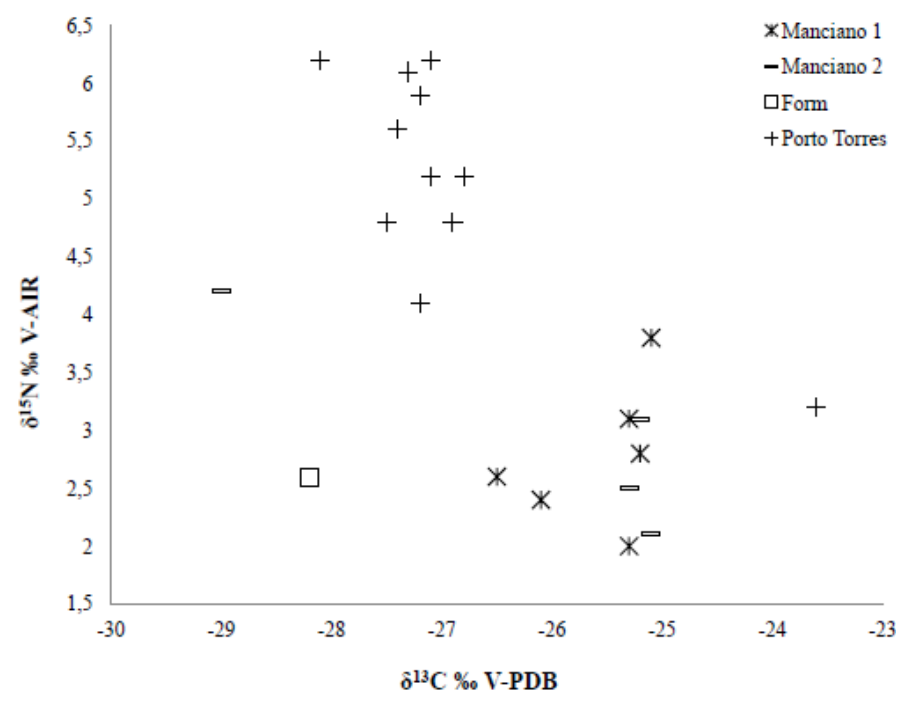

Figure 3. Relation between $\delta^{15} \mathrm{~N} \%$ V-AIR and $\delta^{13} \mathrm{C} \%$ V-PDB in feed samples from Tuscan and Sardinian samples.

Toscano DOP” based on stable isotopes technique. Watering water and milk water samples were subjected to $\delta^{18} \mathrm{O}$ and $\delta \mathrm{D}$ isotopic analysis trying to trace the intake water, referred as "source water", in the final milk product. Moreover, $\delta^{13} \mathrm{C}$ and $\delta^{15} \mathrm{~N}$ isotopes analysis was performed on samples from all feed types trying to certify their origin and their production according to the required agricultural practices. At first the interest was devoted to the development of the technique for extracting the water from milk using a cryogenic vacuum line through which were allowed to improve the sensitivity of the analytical method for deuterium analysis. Indeed, a cryogenic vacuum line was set up in Institute of Geosciences and Earth Resources, CNR, Pisa leading to a sensitivity of $0.1 \%$ for ${ }^{18} \mathrm{O}$ and $1 \%$ for ${ }^{2} \mathrm{H}$. Through the investigation of the relationship between milk and intake water from sheep several factors that control the isotopic enrichment of Sardinian and Tuscan milk samples were highlighted. Sardinian milk samples present a less pronounced enrichment in deuterium compared to those from Manciano with the slopes of the $\delta \mathrm{D} v s$. $\delta^{18} \mathrm{O}$ "mixing lines" between watering water and milk water samples to be established as "1. 7" for Porto Torres and "4.0" for Manciano. The feed samples (excluding two cases) presented typical $\delta^{13} \mathrm{C}$ values of $\mathrm{C} 3$ plants $\left(-22 \% 0<\delta^{13} \mathrm{C}<-30 \%\right.$ ) however Porto Torres (Sardinia) samples were characterized by an isotopic composition more depleted in $\delta^{13} \mathrm{C}$ than those of Manciano (Tuscany). In contrast, regarding $\delta^{15} \mathrm{~N}$ values in feed supplies, Tuscan samples are generally less positive than those from Sardinia. This has been attributed to the different precipitation regime in the two geographical areas that almost completely justifies the variation in $\delta^{15} \mathrm{~N}$ isotopes according to the slope $-0.39 \%$ o $\delta^{15} \mathrm{~N} / 100 \mathrm{~mm}^{-1}$ reported by Heaton [38] (2.5\% theoretical difference against $2.7 \%$ observed). In conclusion, results show that the isotopic ratios $\mathrm{D} /{ }^{1} \mathrm{H}$ ${ }^{18} \mathrm{O} /{ }^{16} \mathrm{O}$ in water and ${ }^{15} \mathrm{~N} /{ }^{14} \mathrm{~N}-{ }^{13} \mathrm{C} /{ }^{12} \mathrm{C}$ in feed supplied to livestock are correlated with the area of origin. In fact, the climatic and geographical characteristics of the study areas (Tuscan and Sardinia) were reflected in the isotopic composition of the sheep watering water and in the isotopic composition of locally grown feed.

\section{References}

1. Martin GJ, Mazure M, Jouitteau C, Martin YL, Aguile L (1999) Characterization of the geographic origin of Bordeaux wines by a combined use of isotopic and trace element measurements. Am J Enol Vitic 50: 409-417
2. Ogrinc N, Košir IJ, Kocjancic M, Kidric J (2001) Determination of authenticity, regional origin, and vintage of Slovenian wines using a combination of IRMS and SNIF-NMR analyses. J Agric Food Chem 49: 1432.

3. Calderone G, Naulet N, Guillou C, Reniero F (2004) Characterization of European wine glycerol: stable carbon isotope approach. J Agric Food Chem 52: 5902-5906. [Crossref]

4. Flamini R, Panighel A (2006) Mass spectrometry in grape and wine chemistry. Part II: The consumer protection. Mass Spectrom Rev 25: 741-774. [Crossref]

5. Niculaua M, Cosofret S, Cotea VV, Nechita CB, Odageriu G (2006) Consideration on stable isotopic determination in Romanian wines. Cercetari Agronomice in Moldova 39: 25-31.

6. Bréas O, Thomas F, Zeleny R, Calderone G, Jamin E, et al. (2007) Performance evaluation of elemental analysis/isotope ratio mass spectrometry methods for the determination of the $\mathrm{D} / \mathrm{H}$ ratio in tetramethylurea and other compounds-results of a laboratory inter-comparison. Rapid Commun Mass Spectrom 21: 1555-1560.

7. Calderone G, Guillou C, Reniero F, Naulet N (2007) Helping to authenticate sparkling drinks with $13 \mathrm{C} / 12 \mathrm{C}$ of $\mathrm{CO} 2$ by gas chromatography-isotope ratio mass spectrometry. Food Res Int 40: 324-331.

8. Guillou C, Koziet J, Rossmann A, Martin GJ (2010) Determination of the 13C contents of organic acids and sugars in fruit juices: an inter-comparison study. Analytica Chimica Acta 388: 137-143.

9. Pîrnau A, Bogdan M, Magdas D, Statescu D (2013) Isotopic Analysis of some Romanian Wines by 2H NMR and IRMS. Food Biophysics: 24-28.

10. Clark I, Fritz P (1997) Environmental isotopes in hydrogeology. New York: Lewis Publishers, pp: 35-78.

11. O'Leary MH (1988) Carbon isotopes in photosynthesis. Bio-Science 38: 328-336.

12. Ehleringer JR, Monson RK (1993) Evolutionary and ecological aspects of photosynthetic pathway variation. Annual Review of Ecology and Systematics 24: 411439 .

13. Kornexl BE, Werner T, Rossmann A, Schmidt HL (1997) Measurement of the stable isotope abundances in milk and milk ingredients - a possible tool for origin assignment and quality control. Z Lebensm Unters Forsch 205: 19-24.

14. Rossmann A, Kornexel BE, Versini G, Pichlmayer F, Lamprecht G (1998) Origin assignment of milk from alpine regions by multielement stable isotope ratio analysis (Sira). La Rivista di Scienza dell'Alimentazione 1: 9-21.

15. Manca G, Camin F, Color GC, Del Caro A, Depentori D, et al. (2001) Characterization of the geographical origin of pecorino sardo cheese by casein stable isotope $(13 \mathrm{C} / 12 \mathrm{C}$ and $15 \mathrm{~N} / 14 \mathrm{~N}$ ) ration and free amino acid ratios. Journal of Agricultural and Food Chemistry 49: 1404-1409.

16. Chiacchierini E, Bogoni P, Franco MA, Giaccio M, Versini G (2002) Characterization of the regional origin of sheep and cow cheeses by casein stable isotope $13 \mathrm{C} / 12 \mathrm{C}$ and $15 \mathrm{~N} / 14 \mathrm{~N}$ ratios. Journal of Commodity Science 41(IV): 303-315.

17. Kottek M, Grieser J, Beck C, Rudolf B, Rubel F (2006) World Map of the KöppenGeiger climate classification updated. Meteorol Z 15: 259-263.

18. Hilkert AW, Avak H (2004) Application note 30048: 18O-Equilibration on Water Fruit Juice and Wine Using Thermo Scientific GasBench II. Thermo Fisher Scientific, Bremen, Germany.

19. Duhr A, Hilkert AW (2004) Application note 30049: Automated H2/H2O Equilibration for dD Determination on Aqueous Samples Using Thermo Scientific GasBench II Thermo Fisher Scientific, Bremen, Germany.

20. Craig H (1961) Isotopic Variations in Meteoric Waters. Science 133: 1702-1703. [Crossref]

21. Doveri M, Mussi M (2014) Water isotopes as environmental tracers for groundwate flow understanding: an application on fractured aquifer systems in the ScansanoMagliano in Toscana area (southern Tuscany- Italy). Water 6: 2255-2277.

22. Longinelli A, Selmo E (2003) Isotopic composition of precipitation in Italy: a first overall map. J Hydrol 270: 75-88.

23. Ritz P, Cole TJ, Davies PS, Goldberg GR, Coward WA (1996) Interactions between $2 \mathrm{H}$ and $18 \mathrm{O}$ natural abundance variations and DLW measurements of energy expenditure. Am J Physiol 271: E302-E308. [Crossref]

24. Murphy MR (1992) Water metabolism of dairy cattle. J Dairy Sci 75: 326-333. [Crossref] 
25. Kohn MJ (1996) Predicting animal d180: accounting for diet and physiological adaptation. Geochim Cosmochim Acta 60: 4811-4829.

26. Camin F, Perini M, Colombari G, Bontempo L, Versini G (2008) Influence of dietary composition on the carbon, nitrogen, oxygen and hydrogen stable isotope ratios of milk. Rapid Commun Mass Spectrom 22: 1690-1696.

27. Minson DJ, Ludlow MM, Troughton JH (1975) Differences in natural carbon isotope ratios of milk and hair from cattle grazing tropical and temperate pastures. Nature 256: 602. [Crossref]

28. Metges C, Kempe K, Schmidt HL (1990) Dependence of the carbon-isotope contents of breath carbon dioxide, milk, serum and rumen fermentation products on the $\mathrm{d} 13 \mathrm{C}$ value of food in dairy cows. British Journal of Nutrition 63: 187-196.

29. Masud Z, Vallet C, Martin GJ (1999) Stable isotope characterization of milk components and whey ethanol. J Agric Food Chem 47: 4693-4699. [Crossref]

30. Knobbe N, Vogl J, Pritzkow W, Panne U, Fry H, et al. (2006) C and N stable isotope variation in urine and milk of cattle depending on the diet. Anal Bioanal Chem 386 : 104-108. [Crossref]

31. Crittenden RG, Andrew AS, LeFournour M, Young MD, Middleton H, et al. (2007) Determining the geographic origin of milk in Australasia using multi-element stable isotope ratio analysis. International Dairy Journal 17: 421-428.

32. Molkentin J, Giesemann A (2007) Differentiation of organically and conventionally produced milk by stable isotope and fatty acid analysis. Analytical and Bioanalytical Chemistry 388: 297-305.

33. Molkentin J (2009) Authentication of organic milk using delta13C and the alphalinolenic acid content of milk fat. J Agric Food Chem 57: 785-790. [Crossref]

34. Molkentin J, Giesemann A (2010) Follow-up of stable isotope analysis of organic versus conventional milk. Anal Bioanal Chem 398: 1493-1500. [Crossref]

35. Sacco D, Brescia MA, Sgaramella A, Casiello G, Buccolieri A, et al. (2009) Discrimination between southern Italy and foreign milk samples using spectroscopic and analytical data. Food Chem 114: 1559-1563.

36. Evans RD, Ehleringer JR (1994) Plant d15N values along a fog gradient in the Atacama Desert, Chile. Journal of Arid Environments 28: 189-193.

37. Wagner H (2005) Stable isotope signatures a method for the determination of the geographic origin? Mitteilungsblatt der Fleischforschung Kulmbach 44: 217-222.

38. Heaton THE (1987) The $15 \mathrm{~N} / 14 \mathrm{~N}$ ratios of plants in South Africa and Namibia: relationship to climate and coastal/saline environments. Oecologia 74: 236-246.

39. Kreitler C, Jones DC (1975) Natural soil nitrate: The cause of the nitrate contamination of groundwater runnels country, Texas. Ground Water 13: 53-62.

40. Yoneyama T (1995) Nitrogen metabolism and fractionation of nitrogen isotopes in plants. In E. Wada, T. Yoneyama, M. Minagawa, T. Ando, \& B. D. Fry(Eds.). Stable isotopes in the biosphere pp: 92-102.

Copyright: (C2017 Dotsika E. This is an open-access article distributed under the terms of the Creative Commons Attribution License, which permits unrestricted use, distribution, and reproduction in any medium, provided the original author and source are credited. 